\title{
ESTUDO RETROSPECTIVO DE 47 COMPLICAÇÕES EM 380 PACIENTES OPERADOS DE CÂNCER RETAL
}

\author{
${ }^{1}$ GERALDO MAGELA GOMES DA CRUZ, ${ }^{1}$ RENATA MAGALI RIBEIRO SILLUZIO FERREIRA, ${ }^{1}$ PETERSON \\ MARTINS NEVES
}

${ }^{1}$ Serviço de Coloproctologia da Santa Casa de Belo Horizonte e Faculdade de Ciências Médicas de Minas Gerais

CRUZ GMG, FERREIRA RMRS, NEVES PM. Estudo Retrospectivo de 47 Complicações em 380 Pacientes Operados de Câncer Retal. Rev bras Coloproct, 2006;26(2):138-155.

RESUMO: No decurso de 31 anos de prática coloproctológica, acumulando um fichário com 24.200 pacientes, 923 (3,8\%) portadores de câncer no intestino grosso, dos quais 870 eram adenocarcinomas colorretais e 53 tumores malignos de ânus e margem de ânus. Dos 870 casos de adenocarcinomas colorretais, 490 (56,3\%) localizavam-se nos cólons e 380 (43,7\%) no reto. O presente trabalho tem como objetivo principal analisar uma casuística de 380 pacientes portadores de câncer retal atendidos de 1965 a 1996, 373 dos quais operados, com ênfase às técnicas cirúrgicas usadas e às $\mathbf{4 7}$ complicações decorrentes das cirurgias e suas correções. $\mathrm{O} C R$ foi mais comum no terço inferior $(172 ; 45,3 \%)$, seguindo o terço superior $(126 ; 33,1 \%)$ e o médio $(82 ; 21,6 \%)$.

A ressecabilidade dos tumores retais de terço superior foi de $88,9 \%$ (112 pacientes), e a retossigmoidectomia abdominal com anastomose manual foi a cirurgia mais praticada (76 pacientes; $60,3 \%$ ). A ressecabilidade dos tumores retais de terço médio foi de $90.2 \%(72$ pacientes), e a retossigmoidectomia abdominal com anastomose manual e mecânica foi a cirurgia mais praticada (40 pacientes; 48,7\%). A ressecabilidade dos tumores retais de terço inferior foi de $89,5 \%$ (154 pacientes), e a amputação abdominoperineal com colostomia definitiva foi a cirurgia mais praticada (154 pacientes; $74,4 \%$ ). A ressecabilidade tumoral foi elevada (338 pacientes; $\mathbf{8 8 , 9 \% ) . ~}$

As cirurgias mais praticadas foram a AAP (135 ou 35,5\%) e a retossigmoidectomia abdominal com anastomose colorretal manual e mecânica (130; 34,3\%). A ocorrência de complicações cirúrgicas imediatas maiores foi de 12,6\% (47 em 380 casos); e a mortalidade cirúrgica foi de $1,6 \%$ ( 6 casos).

As 2 cirurgias mais praticadas apresentaram índices de complicações consideradas baixos: amputação abdominoperineal à Miles com colostomia definitiva - 135 cirurgias com 13 complicações $(9,6 \%)$ e 2 óbitos $(1,5 \%)$; e a retossigmoidectomia abdominal tipo Dixon com anastomose manual e mecânica - 130 cirurgias com 19 complicações $(14,6 \%)$ e 2 óbitos $(1,5 \%)$.

O maior índice de complicações foi da retossigmoidectomia abdômino-endoanal com anastomose cólon-anal mecânica (30,7\%); e o menor foi da amputação abdominoperineal $(9,6 \%)$.

O maior índice de mortalidade foi da retossigmoidectomia abdômino-endoanal com anastomose cólon-anal mecânica (7,7\%); e o menor foi da amputação abdominoperineal $(1,5 \%)$.

Dentre as 47 complicações, as mais comuns foram as relacionadas à própria anastomose (15 deiscências e 6 estenoses), seguidas dos abscessos ( 3 abscessos subfrênicos, 4 abscessos pélvicos e 2 abscessos perineais), da necrose de coto abaixado (4 casos), necrose e desabamento de estoma (4 casos), obstrução de intestino delgado ( 3 casos), hemorragia (4 casos) e lesão cirúrgica do ureter ( 2 casos).

As condutas em cada caso dependeram das condições do paciente, da doença, da evolução e gravidade da complicação e dos recursos técnicos de cada época em que os pacientes foram atendidos.

Descritores: Complicações da cirurgia para câncer retal; cirurgia no câncer retal; câncer no reto; cirurgia retal.

Trabalho realizado no Serviço de Coloproctologia da Santa Casa de Belo Horizonte e Faculdade de Ciências Médicas de Minas Gerais.

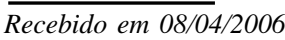

Aceito para publicação em 18/05/2006 


\section{INTRODUÇÃO}

O tratamento do CR é multidisciplinar, envolvendo, sobretudo, três especialistas: o coloproctologista, o oncologista e o radioterapêuta, embora em decorrência de seus aspectos evolutivos outros especialistas tenham que participar da abordagem. A cirurgia é a abordagem mais eficiente e de primeira escolha, embora trabalhos recentes venham mostrando casos de CR incipientes com boa resposta a tratamentos químio e radioterápicos. A radioterapia ocupa lugar de destaque no tratamento dos CR, tanto como complementação anterior ou posterior à cirurgia, como alternativa cirúrgica, e mesmo como opção nas recidivas e nos casos de CR inoperável. Da mesma forma os tratamentos químio e imunoterápicos encontram aplicações inquestionáveis no tratamento do $\mathrm{CR}$.

As cirurgias ressecativas eletivas (ressecção local, por via abdominal, por via abdominoendoanal e por via abdominoperineal), bem como as cirurgias ressecativas não eletivas (cirurgias ampliadas, alargadas, de urgência e paliativas) para CR estão relacionadas na Tabela-1. Os fatores determinantes da escolha da opção cirúrgica são relacionados com

Tabela 1 - Técnicas básicas de cirurgias eletivas para ressecção de câncer retal, cujas representações em siglas são usadas no texto do trabalho.

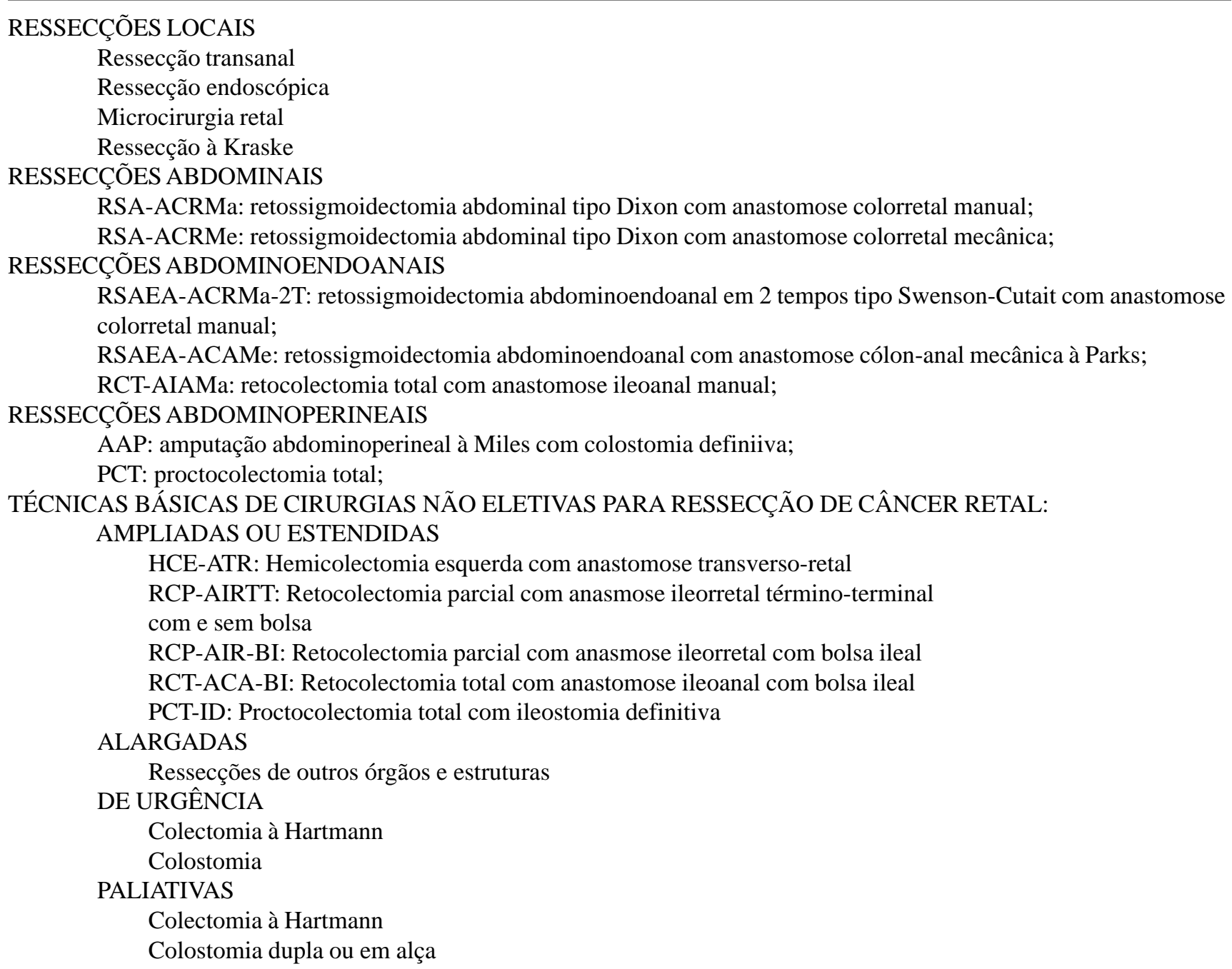


o próprio tumor, com o paciente e com a equipe cirúrgica. Os fatores relacionados com o tumor são altura da localização, aspecto macroscópico, envolvimento circunferencial, fixação aos planos profundos retais e extrarretais, aspecto microscópico, DNA celular, invasão parietal no reto e adenopatia pré-sacra - Beynon (1986) ${ }^{6}$, Kewenter et al. (1994) $)^{57}$ e Wolmark et al. (1986) ${ }^{100}$-. Os fatores relacionados com o paciente são biótipo, idade, sexo, presença de doença metastática, presença de doenças sistêmicas e condições mórbidas afins. Quanto à equipe cirúrgica, são de fundamental importância os recursos médico-hospitalares, a experiência vivida da equipe e a relação médico-paciente. Cada um destes fatores, que por si só pode determinar variações de procedimentos terapêuticos, devem estimular o cirurgião a pensar na radioterapia préoperatória.

A maturidade científica, a experiência de vida e as novas conquistas tecnológicas propedêuticas e terapêuticas levaram os proctologistas a abandonar o parâmetro simplista da "altura do tumor" como o cutelo da balança “amputar/não amputar”. Melhores conhecimentos da anatomia e da distribuição linfática levaram os proctologistas a investirem na ressecção do mesorreto, concluindo que é mais radical e curativa a cirurgia que resseca "reto gordo" que cirurgia que resseca "reto comprido". Com o advento e posterior aperfeiçoamento dos grampeadores, ensejando anastomoses mecânicas cada vez mais baixas e mais seguras, a escolha "amputar / não amputar transformou-se em uma escolha de conteúdo mais técnico e menos pessoal, mais científica e menos neurótica.

\section{OBJETIVO}

Entre 1965 e 1996 tivemos a oportunidade de acompanhar 380 pacientes portadores de CR. Todos os pacientes foram seguidos e operados pelo mesmo médico e das cirurgias participou a própria equipe do autor. O objetivo deste trabalho é estudar estes 380 pacientes portadores de CR submetidos a várias cirurgias ressecativas, analisando as 47 complicações decorrentes das várias técnicas cirúrgicas usadas e os recursos terapêuticos cirúrgicos utilizados na resolução das complicações.
Um dos objetivos deste trabalho é, ainda, constituir-se, talvez em um dos últimos trabalhos dedicados a tantas técnicas cirúrgicas (ressecção local, retossigmoidectomia abdominal tipo Dixon com anastomose colorretal manual, retossigmoidectomia abdominal tipo Dixon com anastomose colorretal mecânica; retossigmoidectomia abdominoendoanal em 2 tempos tipo Swenson-Cutait com anastomose colorretal manual, retossigmoidectomia abdominoendoanal com anastomose cólon-anal mecânica à Parks, retocolectomia total com anastomose ileoanal manual, amputação abdominoperineal à Miles com colostomia definitiva, proctocolectomia total, retossigmoidectomia abdômino-retrorretal), em uma época em que novos conceitos cirúrgicos e oncológicos, aliados a novos recursos tecnológicos vieram a reduzir este imenso manancial de técnicas a praticamente 4 (ressecção local, retossigmoidectomia abdominal com anastomose colorretal e cólon anal mecânica, além da amputação abdominoperineal).

\section{CASUÍSTICA - PACIENTES E MÉTODOS}

No decurso de 31 anos de prática coloproctológica, de 1965 a 1996, acumulamos um fichário com 24.200 pacientes, $923(3,8 \%)$ dos quais eram portadores de câncer no intestino grosso, e destes, 870 $(94,3 \%)$ eram adenocarcinomas colorretais. Dos 870 casos de adenocarcinomas colorretais, 490 (56,3\%) localizam-se nos cólons e $380(43,7 \%)$ no reto. Este trabalho é um estudo de 380 pacientes portadores de câncer no reto, no tocante às 47 complicações decorrentes das cirurgias às quais foram submetidos, salientando-se as abordagens cirúrgicas destas complicações (Tabela-2).

Tabela 2 - Distribuição de 380 casos de pacientes portadores de câncer retal, por alturas de localizações no reto, atendidas de 1965 a 1996.

\begin{tabular}{lrr}
\hline Terços do Reto & N & \% \\
\hline Terço superior & 126 & 33,1 \\
Terço médio & 82 & 21,6 \\
Terço inferior & 172 & 45,3 \\
Total & 380 & 100,0 \\
\hline
\end{tabular}




\section{RESULTADOS}

\section{Distribuição dos tumores por altura de localização no reto:}

Foi a seguinte a distribuição dos CR por alturas de localizações no reto (Tabela-2) com base no exame proctológico: $126(33,1 \%)$ no terço superior, 82 $(21,6 \%)$ no terço médio e $172(45,3 \%)$ no terço inferior do reto.

\section{Tratamento cirúrgico dos 380 pacientes portadores de câncer retal:}

Tratamento cirúrgico e complicações posoperatórias em 126 pacientes portadores de CR de terço superior de reto: A Tabela-3 mostra que dos 126 pacientes 123 foram levados à cirurgia (97,6\%), 112 tiveram seus tumores ressecados $(88,9 \%)$; e enumera todas as cirurgias realizadas nos 123 pacientes operados (97,6\%): ressecção local (7 ou 5,5\%); retossigmoidectomia abdominal tipo Dixon com anastomose manual ( 76 ou $60,3 \%$ ); retossigmoidectomia abdominal tipo Dixon com anastomose mecânica ( 14 ou 11,1\%); retossigmoidectomia abdominoendoanal em 2 tempos tipo Swenson-Cutait com anastomose colorretal manual (8 ou 6,3\%); retossigmoidectomia abdominoendoanal com anastomose cólon-anal mecânica à Parks (2 ou 1,6\%); retocolectomia total com anastomose ileo-anal manual ( 5 ou $3,4 \%$ ); além de tumores não ressecáveis (11 ou 8,7\%); e pacientes não operados ( 3 ou $2,4 \%)$.

Tratamento cirúrgico e complicações posoperatórias em 82 pacientes portadores de CR de terço médio de reto: a Tabela- 3 mostra que dos 82 pacientes 80 foram levados à cirurgia $(97,5 \%), 72$ tiveram seus tumores ressecados $(90,2 \%)$; e enumera todas as cirurgias realizadas nos 80 pacientes operados $(97,5 \%)$ : ressecção local (4 ou 4,9\%); retos-

Tabela 3 - Tratamento cirúrgico dos 380 pacientes portadores de câncer retal por alturas no reto.

\begin{tabular}{|c|c|c|c|c|c|c|c|c|}
\hline \multirow[t]{3}{*}{ Técnicas cirúrgicas } & \multicolumn{6}{|c|}{ TU distribuídos por terços } & \multicolumn{2}{|c|}{ Total } \\
\hline & \multirow[b]{2}{*}{$\mathbf{N}$} & erior & \multicolumn{2}{|c|}{ Médio } & \multicolumn{2}{|c|}{ Inferior } & & \\
\hline & & $\%$ & $\mathbf{N}$ & $\%$ & $\mathbf{N}$ & $\%$ & $\mathbf{N}$ & $\%$ \\
\hline RL & 75,5 & 4 & 4,9 & 16 & 9,3 & 27 & 7,1 & \\
\hline RSA-ACRMa (Dixon) & 76 & 60,3 & 28 & 34,1 & 0 & 0 & 104 & 27,4 \\
\hline RSA-ACRMe (Dixon) & 14 & 11,1 & 12 & 14,6 & 0 & 0 & 26 & 6,9 \\
\hline RSAEA-ACRMa-2T & 86,3 & 14 & 17,0 & 0 & 0 & 22 & 5,8 & \\
\hline RSAEA-ACAMe (Parks) & 21,6 & 4 & 4,9 & 7 & 4,1 & 13 & 3,4 & \\
\hline RCT-AIAMa & 53,4 & 2 & 2,5 & 0 & 0 & 7 & 1,8 & \\
\hline AAP - MILES & 00 & 7 & 8,5 & 128 & 74,4 & 135 & 35,5 & \\
\hline PCT & 00 & 0 & 0 & 3 & 1,7 & 3 & 0,8 & \\
\hline RSARR-Duhamel & 00 & 1 & 1,2 & 0 & 0 & 1 & 0,3 & \\
\hline Total de TU ressecados & 112 & $\mathbf{8 8 , 9}$ & 72 & 90,2 & 154 & 89,5 & 338 & 88,9 \\
\hline TU irressec. - Colostomia & 11 & 8,7 & 8 & 9,8 & 16 & 9,3 & 35 & 9,2 \\
\hline Pacientes operados & 123 & 97,6 & 80 & $\mathbf{9 7 , 5}$ & 170 & 98,8 & 373 & 98,1 \\
\hline Pacientes não operados & 32,4 & 2 & 2,5 & 2 & 1,2 & 7 & 1,8 & \\
\hline Pacientes com CR & 126 & 100 & 82 & 100 & 172 & 100 & 380 & 100 \\
\hline
\end{tabular}

RL: resseção local;

RSA-ACRMa: retossigmoidectomia abdominal tipo Dixon com anastomose colorretal manual;

RSA-ACRMe: retossigmoidectomia abdominal tipo Dixon com anastomose colorretal mecânica;

RSAEA-ACRMa-2T: retossigmoidectomia abdominoendoanal em 2 tempos tipo Swenson-Cutait com anastomose colorretal manual;

RSAEA-ACAMe: retossigmoidectomia abdominoendoanal com anastomose cólon-anal mecânica à Parks;

RCT-AIAMa: retocolectomia total com anastomose ileoanal manual;

AAP: amputação abdominoperineal à Miles com colostomia definiiva;

PCT: proctocolectomia total;

RSARR: retossigmoidectomia abdômino-retrorretal à Duhamel. 
sigmoidectomia abdominal tipo Dixon com anastomose manual (28 ou $34,1 \%)$; retossigmoidectomia abdominal tipo Dixon com anastomose mecânica (12 ou $14,6 \%$ ); retossigmoidectomia abdominoendoanal em 2 tempos tipo Swenson-Cutait com anastomose colorretal manual (14 ou $17,0 \%$ ); retossigmoidectomia abdominoendoanal com anastomose cólon-anal mecânica à Parks (4 ou 4,9\%); retocolectomia total com anastomose ileo-anal manual ( 2 ou 2,5\%); amputação abdominoperineal à Miles (7 ou 8,5\%); além de tumores não ressecáveis ( 8 ou $9,8 \%$ ); e pacientes não operados (2 ou $2,5 \%)$.

Tratamento cirúrgico e complicações posoperatórias em 172 pacientes portadores de CR de terço inferior de reto: a Tabela-3 mostra que dos 172 pacientes 170 foram levados à cirurgia $(98,8 \%), 154$ tiveram seus tumores ressecados $(89,5 \%)$; e enumera todas as cirurgias realizadas nos 170 pacientes operados (98,8\%): ressecção local (16 ou 9,3\%); retossigmoidectomia abdominoendoanal com anastomose cólon-anal mecânica à Parks ( 7 ou 4,1\%); amputação abdominoperineal à Miles (154 ou $74,4 \%$ ); proctocolectomia total com ileostomia definitiva ( 3 ou $1,7 \%$ ); além de tumores não ressecáveis (16 ou 9,3\%); e pacientes não operados ( 2 ou $1,2 \%$ ).

Sinopse das cirurgias em pacientes com CR: a Tabela-3 mostra que dos 380 pacientes portadores de CR 373 foram levados à cirurgia $(98,1 \%), 338$ tiveram seus tumores ressecados $(88,9 \%)$; e enumera todas as cirurgias realizadas nos 373 pacientes operados $(98,1 \%)$ : ressecção local $(27$ ou $7,1 \%)$; retossigmoidectomia abdominal tipo Dixon com anastomose manual (104 ou 27,4\%); retossigmoidectomia abdominal tipo Dixon com anastomose mecânica (26 ou $6,9 \%$ ); retossigmoidectomia abdominoendoanal em 2 tempos tipo Swenson-Cutait com anastomose colorretal manual (22 ou 5,8\%); retossigmoidectomia abdominoendoanal com anastomose cólon-anal mecânica à Parks (13 ou $3,4 \%$ ); retocolectomia total com anastomose ileo-anal manual (7 ou 1,8\%); amputação abdominoperineal à Miles (135 ou 35,5\%); proctocolectomia total com ileostomia definitiva (3 OU $0,8 \%$ ); retossigmoidectomia abdominal retrorretal ( 1 ou $0,3 \%)$; além de tumores não ressecáveis (35 ou $9,2 \%$ ); e pacientes não operados (7 ou 1,8\%).

\section{Complicações imediatas maiores e mortalidade cirúrgica por técnicas cirúrgicas usadas:}

Foram consideradas as complicações ditas "maiores", ou seja, complicações de menor importância, como abscessos de parede, incontinência e infecção urinária passageira, hematomas, entre outras, não foram computadas. Da mesma forma somente foram consideradas complicações imediatas, ou seja, complicações tardias e de longo prazo, como incontinência urinária permanente, bexiga neurogênica, impotência sexual, esterilidade, entre outras, não foram consideradas.

A Tabela-4 mostra as incidências de complicações e óbitos ocorridos em todas as cirurgias praticadas em todos os pacientes: ressecção local, 27 cirurgias com 2 complicações $(7,4 \%)$ e nenhum óbito (0\%); retossigmoidectomia abdominal tipo Dixon com anastomose manual, 104 cirurgias com 13 complicações $(12,5 \%)$ e 2 óbitos $(1,9 \%)$; retossigmoidectomia abdominal tipo Dixon com anastomose mecânica, 26 cirurgias com 6 complicações $(23,0 \%)$ e nenhum óbito $(0 \%)$; retossigmoidectomia abdominoendoanal em 2 tempos tipo Swenson-Cutait com anastomose colorretal manual, 22 cirurgias com 5 complicações $(22,7 \%)$ e um óbito $(4,5 \%)$; retossigmoidectomia abdominoendoanal com anastomose cólon-anal mecânica à Parks (13 cirurgias com 4 complicações $(30,7 \%)$ e um óbito $(7,7 \%)$; retocolectomia total com anastomose ileo-anal manual, 7 cirurgias com 2 complicações $(28,5 \%)$ e nenhum óbito (0\%); amputação abdominoperineal à Miles com colostomia definitiva, 135 cirurgias com 13 complicações $(9,6 \%)$ e 2 óbitos $(1,5 \%)$; proctocolectomia total com ileostomia definitiva, 3 cirurgias, sem complicações $(0 \%)$ e sem óbitos $(0 \%)$; retossigmoidectomia abdômino-retrorretal, uma cirurgia sem complicação $(0 \%)$ ou óbito (0\%); e colostomia para tumores irressecáveis, 35 cirurgias com 2 complicações $(5,7 \%)$ e nenhum óbito $(0 \%)$; que com os 7 pacientes não operados perfazem 380 pacientes. Na totalização dos 380 pacientes, 338 tiveram seus tumores ressecados $(88,9 \%)$, sendo que destas cirurgias advieram 45 complicações $(13,3 \%)$ e 6 óbitos $(1,8 \%)$; dos 373 pacientes levados à cirurgia $(98,2 \%)$, decorreram 47 complicações $(12,6 \%)$ e 6 óbitos $(1,6 \%)$ (Tabela-4).

Complicações imediatas maiores e mortalidade cirúrgica específica por técnicas cirúrgicas usadas: A 
Tabela 4 - Complicações cirúrgicas e óbitos, por cirurgias realizadas, em 373 pacientes portadores de câncer no reto, atendidos de 1965 a 1996.

\begin{tabular}{lrrrrrr}
\hline Cirurgias & \multicolumn{2}{c}{ Total } & \multicolumn{2}{c}{ Complic. } & \multicolumn{2}{c}{ Óbitos } \\
& N & \% & N & \% & N & \% \\
\hline & 27 & 7,1 & 2 & 7,4 & 0 & 0 \\
RL & 104 & 27,4 & 13 & 12,5 & 2 & 1,9 \\
RSA-ACRMa (Dixon) & 26 & 6,9 & 6 & 23,0 & 0 & 0 \\
RSA-ACRMe (Dixon) & 22 & 5,8 & 5 & 22,7 & 1 & 4,5 \\
RSAEA-ACRMa-2T & 13 & 3,4 & 4 & 30,7 & 1 & 7,7 \\
RSAEA-ACAMe & 7 & 1,8 & 2 & 28,5 & 0 & 0 \\
RCT-AIAMa & 135 & 35,5 & 13 & 9,6 & 2 & 1,5 \\
AAP - MILES & 3 & 0,8 & 0 & 0 & 0 & 0 \\
PCT & 1 & 0,3 & 0 & 0 & 0 & 0 \\
RSARR-Duhamel & 338 & 88,9 & 45 & 13,3 & 6 & 1,8 \\
Total de TU ressecados & $\mathbf{3 5}$ & $\mathbf{9 , 2}$ & $\mathbf{2}$ & $\mathbf{5 , 7}$ & $\mathbf{0}$ & $\mathbf{0}$ \\
Total de TU irressecáveis - colostomia & $\mathbf{3 7 3}$ & $\mathbf{9 8 , 2}$ & $\mathbf{4 7}$ & $\mathbf{1 2 , 6}$ & $\mathbf{6}$ & $\mathbf{1 , 6}$ \\
Total de pacientes operados & $\mathbf{7}$ & $\mathbf{1 , 8}$ & & & & \\
Total de pacientes não operados & $\mathbf{3 8 0}$ & $\mathbf{1 0 0 , 0}$ & $\mathbf{4 7}$ & $\mathbf{1 2 , 6}$ & $\mathbf{6}$ & $\mathbf{1 , 6}$ \\
Total de pacientes com CR & & & & & &
\end{tabular}

$R L:$ resseção local;

RSA-ACRMa: retossigmoidectomia abdominal tipo Dixon com anastomose colorretal manual;

RSA-ACRMe: retossigmoidectomia abdominal tipo Dixon com anastomose colorretal mecânica;

RSAEA-ACRMa-2T: retossigmoidectomia abdominoendoanal em 2 tempos tipo Swenson-Cutait com anastomose colorretal manual;

RSAEA-ACAMe: retossigmoidectomia abdominoendoanal com anastomose cólon-anal mecânica à Parks;

RCT-AIAMa: retocolectomia total com anastomose ileoanal manual;

AAP: amputação abdominoperineal à Miles com colostomia definiiva;

$P C T$ : proctocolectomia total;

RSARR: retossigmoidectomia abdômino-retrorretal à Duhamel.

Tabela-5 mostra as várias complicações decorrentes das várias cirurgias executadas para abordagem de 373 casos de CR: ressecção local (2 complicações, ambas hemorragias); retossigmoidectomia abdominal tipo Dixon com anastomose manual (13 complicações, sendo 7 deiscências de anastomose, 3 estenoses de anastomose, um abscesso subfrênico, uma lesão cirúrgica de ureter e um abscesso pélvico); retossigmoidectomia abdominal tipo Dixon com anastomose mecânica (6 complicações, sendo 4 deiscências de anastomose e 2 estenoses de anastomose); retossigmoidectomia abdominoendoanal em 2 tempos tipo Swenson-Cutait com anastomose colorretal manual (5 complicações, sendo uma estenose e 4 necroses de coto abaixado); retossigmoidectomia abdominoendoanal com anastomose cólon-anal mecânica à Parks (4 complicações, sendo 2 deiscências de anastomoses e um abscesso pélvico); retocolectomia total com anastomose ileo-anal manual (2 complicações, sendo ambas deiscências de anastomose); amputação abdominoperineal à Miles com colostomia definiiva (13 complicações, sendo 2 hemorragias, 2 abscessos subfrênicos, uma lesão de ureter, 2 abscessos pélvicos, 2 abscessos perineais, 2 obstruções de intestino delgado e 2 necroses com desabamento de colostomia); proctocolectomia total com ileostomia definitiva (sem complicações); retossigmoidectomia abdômino-retrorretal (sem complicações); e colostomia para tumores irressecáveis (2 complicações, sendo ambas necrose com desabamento de colostomia); que com os 7 pacientes não operados perfazem 380 pacientes. $\mathrm{Na}$ totalização de 373 pacientes operados, decorreram 47 complicações ( $\%$ ), sendo 4 casos de hemorragia, 15 de deiscência de anastomose, 6 de estenose de anastomose, 3 de abscesso subfrênico, 2 de lesão cirúrgica de ureter, 4 de abscesso pélvico, 4 casos de necrose de coto abaixado, 2 de abscesso perianal, 3 de obstrução de intestino delgado e 4 de necrose e desabamento de colostomia. 
Tabela 5 - Complicações cirúrgicas específicas em 47 pacientes dentre 373 operados em decorrência de câncer no reto em 380 pacientes atendidos de 1965 a 1996.

\begin{tabular}{|c|c|c|c|c|c|c|c|c|c|c|c|}
\hline \multirow[t]{2}{*}{ Cirurgias } & \multicolumn{11}{|c|}{ Complicações Específicas } \\
\hline & $\mathrm{N}$ & $\begin{array}{l}\text { Hemor- } \\
\text { ragia }\end{array}$ & $\begin{array}{l}\text { Deisc } \\
\text { anast }\end{array}$ & $\begin{array}{c}\text { Est } \\
\text { anast }\end{array}$ & $\begin{array}{l}\text { Absc } \\
\text { subfr }\end{array}$ & $\begin{array}{l}\text { Lesão } \\
\text { ureter }\end{array}$ & $\begin{array}{l}\text { Absc } \\
\text { pélv }\end{array}$ & $\begin{array}{l}\text { Necrose } \\
\text { Coto }\end{array}$ & $\begin{array}{l}\text { Absc } \\
\text { peri }\end{array}$ & $\begin{array}{l}\text { Obstr } \\
\text { ID }\end{array}$ & $\begin{array}{l}\text { Necr/ } \\
\text { desab }\end{array}$ \\
\hline RL & 2 & 2 & & & & & & & & & \\
\hline RSA-ACRMa & 13 & & 7 & 3 & 1 & 1 & 1 & & & & \\
\hline RSA-ACRMe & 6 & & 4 & 2 & & & & 4 & & & \\
\hline RSAEA-ACRMa-2T & 5 & & & 1 & & & & & & & \\
\hline RSAEA-ACAMe & 4 & & 2 & & & & 1 & & & 1 & \\
\hline RCT-AIAMa & 2 & & 2 & & & & & & & & \\
\hline AAP - MILES & 13 & 2 & & & 2 & 1 & 2 & & 2 & 2 & 2 \\
\hline PCT & 0 & & & & & & & & & & \\
\hline RSARR-Duhamel & 0 & & & & & & & & & & \\
\hline Irres. - Colostomia & 2 & & & & & & & & & & 2 \\
\hline Total de cirurgias & 47 & 4 & 15 & 6 & 3 & 2 & 4 & 4 & 2 & 3 & 4 \\
\hline \multicolumn{12}{|l|}{ Não Operados } \\
\hline Total de pacientes & & & & & & & & & & & \\
\hline
\end{tabular}

$R L:$ resseção local;

RSA-ACRMa: retossigmoidectomia abdominal tipo Dixon com anastomose colorretal manual;

RSA-ACRMe: retossigmoidectomia abdominal tipo Dixon com anastomose colorretal mecânica;

RSAEA-ACRMa-2T: retossigmoidectomia abdominoendoanal em 2 tempos tipo Swenson-Cutait com anastomose colorretal manual;

RSAEA-ACAMe: retossigmoidectomia abdominoendoanal com anastomose cólon-anal mecânica à Parks;

RCT-AIAMa: retocolectomia total com anastomose ileoanal manual;

AAP: amputação abdominoperineal à Miles com colostomia definiiva;

$P C T$ : proctocolectomia total;

RSARR: retossigmoidectomia abdômino-retrorretal à Duhamel.

Complicações imediatas maiores e mortalidade cirúrgica específica por técnicas cirúrgicas básicas: com finalidade de atender ao objetivo do trabalho, foram afastados os pacientes não operados, os casos de tumores irressecáveis e todas as cirurgias não eletivas, construindo-se uma nova tabela (Tabela-6), constituída por 334 pacientes submetidos às quatro cirurgias básicas, quais sejam: ressecção local, cirurgias ressecativas com anastomose manual, cirurgias ressecativas com anastomose mecânica e amputação abdominoperineal: das 27 cirurgias de ressecção local resultaram 2 complicações $(7,4 \%)$, sem óbitos; das 133 cirurgias ressecativas com anastomose manual resultaram 20 complicações $(15,0 \%)$ e 3 óbitos $(2,2 \%)$; das 39 cirurgias ressecativas com anastomose mecânica resultaram 10 complicações $(23,0 \%)$ com um óbito $(7,7 \%)$; das 135 cirurgias de amputação abdominoperineal decorreram
13 complicações $(9,6 \%)$ com dois óbitos $(1,5 \%)$. Na totalização dos 380 pacientes, 338 tiveram seus tumores ressecados $(88,9 \%)$, sendo que destas cirurgias advieram 45 complicações $(13,3 \%)$ e 6 óbitos $(1,8 \%)$; dos 373 pacientes levados à cirurgia $(98,2 \%)$, decorreram 47 complicações $(12,6 \%)$ e 6 óbitos $(1,6 \%)$ (Tabela-6).

\section{Abordagens terapêuticas dos 47 pacientes com complicações cirúrgicas decorrentes de 373 cirurgias por câncer no reto em 380 pacientes:}

Os 15 pacientes que desenvolveram deiscência de anastomose foram laparotomizados, tendo 9 sido submetidos a colostomia com fechamento do coto, 2 a reanastomose e estoma protetor e 4 a aplicação de pontos na linha anastomótica; todos os 6 pacientes portadores de estenose de anastomose foram laparo- 
Tabela 6 - Complicações cirúrgicas e óbitos, pelos 4 tipos básicos de cirurgias (ressecção local, retossigmoidectomia com anastomose manual, retossigmoidectomia com anastomose mecânica e amputação abdominoperineal) realizadas em 334 pacientes portadores de câncer no reto de 1965 a 1996.

\begin{tabular}{lrrrrrr}
\hline Cirurgias & \multicolumn{2}{c}{ Total } & \multicolumn{2}{c}{ Complicações } & \multicolumn{2}{c}{ Óbitos } \\
& $\mathbf{N}^{\mathbf{0}}$ & $\mathbf{\%}$ & $\mathbf{N}$ & $\mathbf{\%}$ & $\mathbf{N}$ & $\mathbf{\%}$ \\
\hline 1- RL & 27 & 7,1 & 2 & 7,4 & 0 & 0 \\
2- RSA-ACRMa (Dixon) & 133 & 35,0 & 20 & 15,0 & 3 & 2,2 \\
3- RSA-ACRMe (Dixon) & 39 & 10,3 & 10 & 23,0 & 1 & 7,7 \\
4- AAP - MILES & 135 & 35,5 & 13 & 9,6 & 2 & 1,5 \\
Cirurgias desconsideradas (PCT e RSARR) & 4 & 1, & 0 & 0 & 0 & 0 \\
Total de TU ressecados & 338 & 88,9 & 45 & 13,3 & 6 & 1,8 \\
Total de TU irressecáveis - colostomia & 35 & 9,2 & 2 & 5,7 & 0 & 0 \\
Total de pacientes operados & 373 & 98,1 & 47 & 12,6 & 6 & 1,6 \\
Total de pacientes não operados & 7 & 1,8 & & & & \\
Total de pacientes com CR & $\mathbf{3 8 0}$ & $\mathbf{1 0 0 , 0}$ & $\mathbf{4 7}$ & $\mathbf{1 2 , 6}$ & $\mathbf{6}$ & $\mathbf{1 , 6}$ \\
\hline
\end{tabular}

tomizados e submetidos a nova anastomose e estoma protetor. Todos os 4 pacientes que desenvolveram necrose de coto foram laparotomizados, tendo 3 sido submetidos a reabaixamento do coto e um, a estoma. Dos 3 abscessos subfrênicos, 2 foram submetidos a laparotomia e drenagem e um, a drenagem por imagem; dos 4 abscessos pélvicos, 2 foram submetidos a laparotomia e drenagem cirúrgica e 2 a drenagem por imagem; e ambos os abscessos perianais foram drenados cirurgicamente. Os 3 casos de obstrução de intestino delgado foram abordados por laparotomia com tripsia (um) e enterectomia (2). As 4 necroses de colostomia foram abordadas por confecção de novo estoma (2) e laparotomia com confecção de novo estoma (2). Dos 4 casos de hemorragia, os 2 pacientes com hemorragia perineal foram submetidos à transfixação de pedículo vascular, e os 2 com hemorragia intra-abdominal à laparotomia e transfixação de pedículo vascular. Os 2 casos de lesão de ureter foram submetidos a reimplante (um) e anastomose ureteral e drenagem (um) (Tabela-7).

\section{DISCUSSÃO}

\section{Distribuição dos tumores por altura de localização no reto:}

A distância da borda inferior do tumor ao orifício anal deve ser medida, criteriosamente, evitando-se causas de erro, com retoscópio rígido graduado em centímetros. Deve tal medida corresponder à impressão digital do toque. Em tese, até há aproximadamente 20 anos (com grande variação conceitual no mundo e no Brasil) os tumores situados a menos de $7 \mathrm{~cm}$ da linha anal deveriam ser amputados, e os situados a mais desta medida, à cirurgia conservadora ${ }^{16,17,18,19,36,41,44,45,106}$. Já há algum tempo, aproximadamente 20 anos, com novos recursos de anastomose, sobretudo os grampeadores, esta regra foi quebrada, podendo tumores próximos à linha anorretal ser abordados com cirurgias não amputativas $14,21,50,51,52,64,36,106$. Os tumores situados na parede posterior podem ser ressecados sem amputação com distâncias do tumor ao ânus menores que os anteriores e os cirróticos. Às vezes uma intussuscepção pode levar a confusão da verdadeira altura do tumor.

Como mostra a Tabela- 2 os tumores retais foram muito mais freqüentes no terço inferior do reto (172 casos, 45,3\%), seguindo-se o terço superior (126 casos, $33,1 \%$ ) e o terço médio (82 casos, $21,6 \%$ ). Um dos critérios usados para se avaliar a altura dos CR, além do radiológico (enema opaco) e retossigmoidoscopia, é o toque retal: tumores não tocáveis (terço superior), tumores dificilmente tocáveis (terço médio) e tumores facilmente tocáveis ou visíveis invadindo períneo (terço inferior). Certamente este critério deve ter contribuído para diminuir a incidência dos tumores do terço médio ( 82 casos, 21,6\%). Como a medida foi feita pelo toque retal, casos de CR de terço médio 
Tabela 7 - Abordagens terapêuticas dos 47 pacientes com complicações cirúrgicas decorrentes de 373 cirurgias por câncer no reto em 380 pacientes atendidos de 1965 a 1996.

\begin{tabular}{|c|c|c|c|c|c|c|c|c|c|c|}
\hline & \multicolumn{10}{|c|}{ Complicações cirúrgicas específicas } \\
\hline & $\begin{array}{l}\text { Hemor- } \\
\text { ragia }\end{array}$ & $\begin{array}{l}\text { Deisc } \\
\text { anast }\end{array}$ & $\begin{array}{l}\text { Est } \\
\text { anast }\end{array}$ & $\begin{array}{l}\text { Absc } \\
\text { subfr }\end{array}$ & $\begin{array}{l}\text { Lesão } \\
\text { ureter }\end{array}$ & $\begin{array}{l}\text { Absc } \\
\text { pélv }\end{array}$ & $\begin{array}{l}\text { Necrose } \\
\text { Coto }\end{array}$ & $\begin{array}{l}\text { Absc } \\
\text { peri }\end{array}$ & $\begin{array}{l}\text { Obstr } \\
\text { ID }\end{array}$ & $\begin{array}{l}\text { Necr/ } \\
\text { desab }\end{array}$ \\
\hline Total de cirurgias & 4 & 15 & 6 & 3 & 2 & 4 & 4 & 2 & 3 & 4 \\
\hline Lap+Colostomia & & 9 & & & & & & & & \\
\hline Lap+anast+estoma & & 2 & 6 & & & & & & & \\
\hline Lap+pontos & & 4 & & & & & & & & \\
\hline Lap+reabaixamento & & & & & & & 3 & & & \\
\hline Lap+estoma & & & & & & & 1 & & & \\
\hline Drenagem cirúrgica & & & & 2 & & 2 & & 2 & & \\
\hline Drenagem imagem & & & & 1 & & 2 & & 0 & & \\
\hline Lap+tripsia & & & & & & & & & 1 & \\
\hline Lap+enterectomia & & & & & & & & & 2 & \\
\hline Novo estoma & & & & & & & & & & 2 \\
\hline Lap+novo estoma & & & & & & & & & & 2 \\
\hline Tansfixação & 2 & & & & & & & & & \\
\hline Lap+transfixação & 2 & & & & & & & & & \\
\hline Lap+reimplante & & & & & 1 & & & & & \\
\hline Lap+anastomose & & & & & 1 & & & & & \\
\hline
\end{tabular}

podem ter sido incluídos como $\mathrm{CR}$ de terço inferior (172 casos, 45,3\%). Todavia, casos de CR de terço médio, certamente não devem ter sido incluídos como CR de terço superior, uma vez que estes últimos são CR não tocáveis, não gerando dúvidas quanto à sua localização. Todavia não há diferença entre nossos achados e os de alguns autores $26,27,28,29,30,50,51,43,44,45,63$, $64,71,98$.

\section{Cirurgias em câncer retal:}

Cirurgias em CR de terço superior : a cirurgia mais realizada para CR de terço superior (Tabela-3) foi a RSA-ACRMa tipo Dixon (76 casos entre 126 pacientes ou 60,3\%), seguida, de longe, pela RSAACRMe, que continua sendo a cirurgia padrão, pois não sendo a anastomose muito baixa, pode ela ser feita com sutura manual, dispensando os elevados custos de grampeadores. As cirurgias de anastomoses manuais ocuparam um lugar de destaque: 89 cirurgias em 112 pacientes operados de CR de terço superior $(79,4 \%)$. Cirurgias em CR de terço médio : 90,1\% dos 82 casos de CR de terço médio (Tabela-2) tiveram preservação esfincteriana, mantendo o esfíncter e a continuidade intestinal; tendo sido de apenas 9,9\% (7 casos) a incidência de cirurgia amputativa (Tabela-3). Dentre as cirurgias que preservam o esfíncter sobressaiu a RSA-ACRMa por 28 casos $(34,1 \%)$, seguida da 
RSAEA-ACRMa-2T com 14 casos $(17,0 \%)$ (Tabela$3)$.

Cirurgias em CR de terço inferior : somente houve 4 tipos de cirurgias para os $\mathrm{CR}$ de terço inferior, sobressaindo, de forma marcante, a cirurgia amputativa, com 128 casos $(74,4 \%)$, seguida de longe pela ressecção local, com apenas 16 casos $(9,3 \%)$. Este elevado número de AAP pode ser assim explicado: não havia, no início desta série, outra alternativa à AAP, para os CR de terço inferior, a não ser as cirurgias de abaixamento em dois tempos com anastomose cólonanal manual, precárias e com elevados índices de complicações. Assim, para os portadores de CR de terço inferior, o advento da anastomose mecânica com grampeadores significou a maior possibilidade de preservação esfincteriana. Enquanto a RSA-ACAMe surgiu e se desenvolveu como resultado dos grampeadores, as RL passaram a ser uma alternativa viável em decorrência do desenvolvimento de técnicas propedêuticas importantes na avaliação da invasão dos $\mathrm{CR}$, notadamente os recursos de imagens (tomografia computadorizada, ressonância magnética de imagens e sobretudo o ultra-som endorretal).

Sinopse das cirurgias em CR: a cirurgia mais realizada para CR (Tabela-6), independentemente de suas alturas no reto, foi a AAP (135 casos, 35,5\%), seguida de perto pela RSA-ACRMa (104 casos, $27,4 \%$ ), sendo menores as incidências das demais técnicas: RL ( 27 casos, 7,1\%), RSA-ACRMe (26 casos, 6,9\%), RSAEA-ACRMa (22 casos, 5,8\%), RSAEAACAMe (13 casos, 3,4\%), chamando-se a atenção para os pacientes não operados ( 7 casos, $1,8 \%$ ) e tumores irressecáveis (35 casos, 9,2\%). Destarte, à medida que o tempo decorreu, menos cirurgias amputativas passaram a ser feitas, substituídas que foram, em grande parte, pelas anastomoses colorretais e cólon-anais com grampeadores.

Relatos americanos e europeus de vários autores - Beck \& Wexner (1992) ${ }^{3}$, Coller \& Murray (1994) ${ }^{13}$, Corman (1989) ${ }^{14}$, Gordon \& Nivatvongs $(1999)^{46}$, Keighley \& Williams (1997) ${ }^{56}$, Keighley et al. (1996) ${ }^{55}$, Phillips (1998) ${ }^{79}$, Ravitch \& Steichen $(1987)^{80}$, Schiller et al. $(1995)^{88}$, Welter \& Patel (1985) ${ }^{95}$, Wheeless (1988) ${ }^{96}$ e Williams (1996) ${ }^{98}$ - indicam o uso de grampeadores 10 anos, ou mesmo mais, antes do início do uso em nossa casuística, fato que encontra explicação no acesso dificil a tais instrumentos no início da década de 70. Em São Paulo, Rio de Janeiro, Salva- dor e Ceará, segundo Ramos et al. (1997) ${ }^{81}$ os grampeadores passaram a ser usados quase que concomitantemente, da mesma forma, cerca de 10 anos antes do uso, como rotina, em Minas Gerais. A não ser pela diferença de incidência maior, em nossa casuística, de anastomoses manuais sobre as mecânicas, não há diferença estatisticamente significativa entre nossa incidência de técnica cirúrgica preservando esfíncter quando comparada com a literatura mundial e mesmo nacional.

\section{Complicações imediatas maiores e mortalidade na amputação abdominoperineal à Miles:}

Complicações: a AAPé uma cirurgia de grande porte e com índices de complicações pós-operatórias elevados, tanto a longo prazo (impotência sexual, bexiga neurogênica, esterilidade), quanto menores e de soluções freqüentemente clínicas (infecção urinária, abscessos de parede), quanto urgentes e que freqüentemente exigem decisão cirúrgica imediata (hemorragia intra-abdominal e perineal, complicações da colostomia, abscessos pélvicos e perineais), estas últimas, como foi enfatizado nos objetivos do trabalho, escopo deste estudo. A impotência sexual e a bexiga neurogênica, alguns autores têm com elevada freqüência em pacientes idosos - Baslev \& Harling $(1983)^{2}$, Bernstein \& Bernstein (1966) ${ }^{5}$, Bokey et al. $(1990)^{8}$, Burgos et al. (1988) ${ }^{11}$, Cruz (1992, 1996, 2000) 17, 18, 26, 27, Cukier (1970) ${ }^{28}$, Cunsolo et al. $(1989,1990)$ ${ }^{29,30}$, Eickerberg et al. (1976) ${ }^{35}$, Gerstenverg et al. (1980) ${ }^{39}$, Klin \& Ohman (1986) ${ }^{59}$, Rosen et al. (1982) ${ }^{83}$, Santangelo et al. (1987) ${ }^{85}$, Santy et al. (1951) ${ }^{86}$, Walz et al. (1977) ${ }^{93}$ e Yeager \& Van Heerden (1980) ${ }^{103}$-. A ressecção requer dissecção pélvica extensa, que pode redundar em lesão parassimpática (nervi erigentes). A potência sexual do paciente, estando deficiente no préoperatório, pode também ser afetada pelo simples trauma cirúrgico. Todavia, não foram objetos deste estudo tais complicações, mas as complicações maiores e de caráter de urgência: 13 complicações $(9,6 \%)$ em 135 pacientes amputados. Torna-se muito difícil traçar um paralelo entre os níveis de complicações observados por nós $(9,6 \%)$ e outros autores - que variaram de 3,1\% a 21,2\% - Enker et al. (1979) ${ }^{36}$, Bokey $(1990)^{8}$, Cunsolo $(1989)^{30}$, Gillen (1986) ${ }^{40}$, Halpern (1989) ${ }^{52}$, Hughes (1980) ${ }^{54}$ e Rothenberger (1990) ${ }^{84}$, tamanha a discrepância entre os dados da literatura (Tabela-8). Mortalidade: a mortalidade com a amputação 
Tabela 8 - Média percentual de 9.200 AAP por vários autores ${ }^{39}$, não consideradas complicações sistêmicas.

\begin{tabular}{lr}
\hline Complicações & $\%$ \\
\hline Impotência (c/ e s/ esterilidade) & 17,9 \\
Complicações da colostomia & 13,6 \\
Abscessos perineais & 11,6 \\
Hipertrofia prostática benigna & 7,8 \\
Infecção do trato urinário & 8,2 \\
Obstrução I.D. por aderências & 4,1 \\
Doença neurogênica & 3,7 \\
Infecção da parede abdominal & 3,5 \\
Evisceração & 3,4 \\
Hemorragia perineal & 3,1 \\
Estreitamento uretral & 0,8 \\
Fístulas vesicais & 0,8 \\
Hérnia perineal & 0,6
\end{tabular}

Charrier e Loygue (1950), D'Avila (1950), Yodice et al. (1952), Bacon (1956), Black \& Botham (1958), Waugh \& Turner (1958), Turnbull \& Curthbertson (1961), Salvati (1961), Hughes et al. (1962), Goligher (1965), Vidal-Lobo (1966), Candioti (1966), Kratzer (1967), Kennedy et al. (1971), Cutait (1970), Dubois (1971), Habr-Gama (1972), Enker et al. (1979), Bokey (1990), Cunsolo (1989), Gillen (1986), Halpern (1989), Hughes (1980) e Rothenberger (1990)

abdominoperineal em nossa casuística (dois óbitos em 135 pacientes amputados) foi de $1,5 \%$. A menor taxa de incidência de mortalidade, certamente se deve ao fato de a maioria das cirurgias levantadas pelos autores assinalados terem sido realizadas algum tempo antes de nossa análise. E a experiência mostra que a mortalidade cai com o tempo cronológico, em decorrência do desenvolvimento técnico da Medicina. A mortalidade cirúrgica oscila entre os extremos de 0,0\% - Cunsolo (1989) ${ }^{30}$ - e 6,5\% - Shepard (1971) ${ }^{89}$, segundo os seguintes autores: Bordos et al. (1974) 9, 2,9\%; Deddish \& Stearns (1961) ${ }^{34}, 2,0 \%$; Enker et al. (1979) ${ }^{36}$, 6,4\%; Glenn \& McSherry (1966) ${ }^{41}$, 4,7\%; Lockhart-Mummery et al. (1976) ${ }^{67}, 2,1 \%$; Localio et al. (1978) ${ }^{66}, 2,3 \%$; Maclennan et al. (1976) ${ }^{69}, 3,2 \%$; Palumbo \& Sharpe (1968) ${ }^{75}, 4,4 \%$; Stearns $(1974)^{91}, 3,5 \%$; Slanetz et al. (1972) $)^{90}, 5,4 \%$; Strauss et al. (1978) ${ }^{92}, 3,5 \%$; Walz et al. (1977) ${ }^{93}, 4,7 \%$; Williams et al. (1966) ${ }^{98}, 4,3 \%$; Zollinger \& Shepard (1971) ${ }^{102}, 6,5 \%$; Bokey $(1990)^{8}, 3,1 \%$; Cunsolo (1989)30, 0,0\%; Gillen (1986) ${ }^{40}, 2,2 \%$; Halpern $(1989)^{52}, 3,0 \%$; Hughes $(1980)^{54}, 6,3 \%$; Patel (1977)
${ }^{77}, 2,9 \%$; Rosen (1982) ${ }^{83}, 1,7 \%$; Rothenberger (1990) ${ }^{84}, 2,6 \%$ ) (Tabela-9).

\section{Complicações da retossigmoidectomia abdominal à Dixon com anastomose manual:}

Foi a segunda cirurgia mais realizada (104 pacientes), de que resultaram 13 complicações (12,5\%). A complicação mais comum da cirurgia de Dixon foi deiscência de anastomose (7 casos), seguindo-se estenose com e sem fístula cega (3 casos), abscesso subfrênico (1 caso), lesão de ureter (1 caso) e abscesso pélvico (1 caso).

As complicações das RSA-ACRMa baixas, especialmente a deiscência, chegaram a níveis insuportáveis de 15 a $77 \%$, mas decresceram a ótimos níveis (0 a 6,2\%) em decorrência da freqüente implementação dos grampeadores circulares - Antonsen \& Bronborg (1985) $)^{1}$; Cruz (1988) ${ }^{21}$, Cruz (1999), HabrGama (1994) ${ }^{50,51}$, Macklennan et al (1976) ${ }^{69}$, 2000; Santangelo et al (1987) ${ }^{85}$, Santy et al (1951) ${ }^{86,}$ Schiller

Tabela 9 - Mortalidade na amputação abdominoperineal por vários autores.

\begin{tabular}{lc}
\hline Autores & $\%$ \\
\hline Bordos et al. (1974) & 2,9 \\
Deddish \& Stearns (1961) & 2,0 \\
Enker et al. (1979) & 6,4 \\
Glenn \& McSherry (1966) & 4,7 \\
Lockhart-Mummery et al. (1976) & 2,1 \\
Localio et al. (1978) & 2,3 \\
Maclennan et al. (1976) & 3,2 \\
Palumbo \& Sharpe (1968) & 4,4 \\
Stearns (1974) & 3,5 \\
Slanetz et al. (1972) & 5,4 \\
Strauss et al. (1978) & 3,5 \\
Walz et al. (1977) & 4,7 \\
Williams et al. (1966) & 4,3 \\
Zollinger \& Shepard (1971) & 6,5 \\
Bokey (1990) & 3,1 \\
Cunsolo (1989) & 0,0 \\
Gillen (1986) & 2,2 \\
Halpern (1989) & 3,0 \\
Hughes (1962) & 6,3 \\
Patel (1986) & 2,9 \\
Rosen et al. (1982) & 1,7 \\
Rothenberger (1987) & 2,6 \\
\hline
\end{tabular}


Tabela 10 - Retossigmoidectomia abdômino-endoanais - complicações, recidivas tumorais e mortalidade segundo vários autores.

\begin{tabular}{|c|c|c|c|c|c|c|c|c|}
\hline AUTORES & $\begin{array}{l}\text { Infeção } \\
\text { pélvica }\end{array}$ & $\begin{array}{l}\text { Necrose } \\
\text { De coto }\end{array}$ & $\begin{array}{l}\text { Estenose } \mathrm{F} \\
\text { Anastomose }\end{array}$ & $\begin{array}{l}\text { Fístula } \\
\text { se }\end{array}$ & $\begin{array}{l}\text { Impot. } \\
\text { sexual }\end{array}$ & $\begin{array}{c}\text { Perda } \\
\text { ejaculação }\end{array}$ & $\begin{array}{l}\text { Recidiva } \\
0<2 \text { anos }\end{array}$ & $\begin{array}{l}\text { Morta- } \\
\text { lidade }\end{array}$ \\
\hline Charrier $e$ Loygue (1950) & & & & & & & 11,7 & 7,5 \\
\hline D’Avila (1950) & & 5,8 & & & & & & 0 \\
\hline Yodice et al. (1952) & & & & & 4 & & 6 & 10 \\
\hline Bacon (1956) & 5 & 0,9 & & & 7,5 & 4,5 & 16,2 & 3,9 \\
\hline Black \& Botham (1958) & & & & & & & & 5,7 \\
\hline Waugh \& Turner (1958) & & & & & & & & 6,2 \\
\hline \multicolumn{9}{|l|}{ Turnbull \& } \\
\hline Curthbertson (1961) & 13 & 0 & & & & & & 0 \\
\hline Salvati (1961) & 30 & & & & & & & \\
\hline Hughes et al. (1962) & 17 & 3,3 & & & & & & 2,2 \\
\hline Goligher (1965) & 25 & 22,2 & 15 & 7,5 & & & & 12,5 \\
\hline Vidal-Lobo (1966) & & 6 & & & & & & 12 \\
\hline Candioti (1966) & & 23 & 3 & 7,6 & & & & 11,5 \\
\hline Kratzer (1967) & & 1,25 & & & 6 & & & 3,7 \\
\hline Kennedy et al. (1971) & 18 & 4,6 & & 5 & & & 9 & 12 \\
\hline Cutait (1970) & 12,5 & 2,2 & & & & & & \\
\hline Dubois (1971) & 12 & 4 & & & & & & \\
\hline Habr-Gama (1972) & 10 & 6 & 6 & 16,6 & 25 & & 8 & \\
\hline
\end{tabular}

et al (1995) ${ }^{88}$, Fazio (1984) ${ }^{37}$-. Nossos achados não são discrepantes quando comparados a achados da literatura, por parte de vários autores, dentre os quais Broadwell \& Jackson (1982) ${ }^{10}$; Chassin (1980) ${ }^{12}$; Glockner \& Sterling (1982) ${ }^{42}$; Green (1966) ${ }^{47}$; HabrGama et al. (1994) ${ }^{50}$; Kretschmer (1978) ${ }^{60}$; Leenen \& Kuypers (1989) ${ }^{64}$; Pearl et al. (1985) ${ }^{78}$, que descrevem complicações de $11,2 \%$ a $77 \%$ (Tabela-10).

\section{Complicações da retossigmoidectomia à Dixon com anastomose mecânica:}

Das 26 cirurgias de retossigmoidectomia abdominal tipo Dixon com anastomose mecânica (Tabela-4) resultaram 6 complicações $(23,0 \%)$ e nenhum óbito (0\%). Os índices de complicações das RSA-ACRMe diminuíram para níveis melhores ( 0 a $6,2 \%$ ) em decorrência da freqüente implementação dos grampeadores circulares $1,21,50,51,52,69,76,85,86,88$.

\section{Ressecção local:}

Foi realizada em 27 pacientes $(7,1 \%)$, delas resultando 2 casos de hemorragia $(7,1 \%)$, ambos resol- vidos com ligadura vascular. Devem ser consideradas a dor, a incontinência, a deiscência de sutura, a hemorragia, as fistulas, os abscessos, as estenoses e as recidivas locais, como assinalam Bokey et al. $(1990)^{8}$, Burgos et al. (1988) ${ }^{11}$; Cruz (1992) ${ }^{16,17}$, Cruz (1996) ${ }^{18}$, Cukier $(1970)^{28}$, Cunsolo et al. (1989) $)^{29}$, Eickerberg et al. (1976) ${ }^{35}$, Gerstenverg et al. (1980) 39, Santangelo et al. (1987) ${ }^{85}$, Santy et al. (1951) ${ }^{86}$, Walz et al. (1977) ${ }^{93}$ e Yeager \& Van Heerden (1980) ${ }^{103}$.

Não houve diferença estatísticamente significante (baixo número de casos) de nossos resultados $(11,1 \%)$ com os de alguns autores, como Bokey et al. $(1990)^{8}$, Burgos et al. (1988) ${ }^{11}$; Cruz (1992) ${ }^{16,17}$, Cruz (1996) ${ }^{18}$, Cukier (1970) ${ }^{28}$, Cunsolo et al. $(1989)^{29}$, que apontam índices de complicações entre 4,2\% e $15,2 \%$

\section{Retossigmoidectomia abdominoendoanal em 2 tempos tipo Swenson-Cutait com anastomose colorretal manual:}

A retossigmoidectomia abdominoendoanal em 2 tempos tipo Swenson-Cutait com anastomose colorretal manual (RSAEA-ACRMa2T) foi realizada 
em 22 pacientes, com 5 complicações $(22,7 \%)$ e um óbito $(4,5 \%)$;

As complicações decorrentes das RSAEAACRMa2T, não obstante a técnica ter sido de remoção total ou parcial do reto, com anastomose imediata ou retardada, com modificações de cunho pessoal ou não, são elevadas, como mostra levantamento que consta da Tabela-10, extraído, inclusive com o texto de Cruz (2002) ${ }^{27}$ : "a infecção pélvica vai de 5\% relatado por Bacon (1945) até 30\% referido por Salvati (1976), a necrose de coto distal oscila entre 0\% com Turnbull (1966) e Curthbertson (Curthbertson \& Kaye, 1978), e 23\% na casuística de Candioti (1976); a estenose ficou entre 3\% na série de Candioti (1976) e 15\% na série de Goligher (1951, 1965), ficando a incidência de fístula entre $5 \%$ (Kennedy et al.,1970) e 7,5\% (Candioti, 1976); a mortalidade cirúrgica, que figura no mesmo quadro, oscilou entre 0\% na casuística de Turnbull (1966) e Curthbertson (1966) e 12,5\% na série de Goligher (1965). No tocante às recidivas tumorais ao nível da linha anastomótica, Charrier e Loygue (1950) relatam 11,7\%, Yodice (1952) 6\%, Bacon (1945) $16,2 \%$ e Kennedy et al. (1970) $9 \%$ em um período de tempo inferior a 2 anos". A impotência sexual e manifestações urinárias ocorrem freqüentemente, não só nos abaixamentos, mas em todas as cirurgias que manipulam o reto, como as amputações e as retossigmoidectomias abdominais. A grande maioria das manifestações urinárias, com o correr do tempo, desaparece. Já a impotência sexual pode decorrer de lesão nervosa, mas muito freqüentemente ocorre em pacientes velhos cuja potência sexual, anterior à cirurgia, era fraca. Assim, na revisão da literatura, houve índices de complicações oscilando entre $3,0 \%$ e $23,0 \%$, enquanto em nossa casuística este índice foi de 22,7, quase o limite superior, fato provavelmente devido ao baixo número de casos e conseqüente menor experiência.

\section{Retossigmoidectomia abdominoendoanal com anastomose cólon-anal mecânica à Parks:}

Foi praticada em apenas 13 pacientes, ocorrendo 4 complicações $(30,7 \%)$ e um óbito $(7,7 \%)$, sendo que a falta de experiência pelo baixo número de casos justifica os elevados índices de complicações.
O pequeno número de casos não justifica comparação com a literatura.

Complicações imediatas maiores e mortalidade dos estomas componentes da amputação, como protetor de anastomoses e como abordagem de pacientes com câncer irressecáveis:

Ocorreram 4 complicações de colostomias: 2 em 35 cirurgias para tumores irressecáveis $(5,7 \%)$, sem óbito; e 2 em 135 colostomias em cirurgias de amputação abdominoperineal (Tabelas- 5 e 6).

Destarte, houve apenas 4 complicações em 170 pacientes submetidos à colostomia abdominal terminal (35 pacientes irressecáveis e 135 pacientes submetidos à amputação abdominoperineal) (2,3\%) (Tabelas-5 e $6)$. Os estomas terminais podem ser sede de complicações, algumas decorrentes de uso inadequado de técnicas cirúrgicas (iatrogênicas), outras em decorrência de constituição do próprio paciente (e.g., obesidade, desnutrição, abdome abaulado, sedentarismo, excesso de exercícios físicos, etc.), e ainda outras provenientes do estado de saúde (e.g., múltiplas incisões cirúrgicas no abdome, ascite, caquexia, doença maligna disseminada, hepatopatias, diabete, uso de determinados medicamentos, etc.). Entre as complicações destacam-se as hérnias parestômicas, os prolapsos, as retrações, os abscessos, a isquemia, a necrose, a recidiva da doença no próprio estoma, as varizes e a hemorragia. Em nosso material foi observada recidiva da doença no próprio estoma, que não consideramos como complicação da colostomia, mas como evolução da própria doença. Os baixos índices de complicações observados em nossa casuística não destoam dos relatados por vários autores - Broadwell \& Jackson (1982) ${ }^{10}$, Chassin (1980) ${ }^{12}$; Glockner \& Sterling (1982) ${ }^{42}$, Green (1966), HabrGama et al. (1994) $)^{48,49,50}$, Kretschmer $(1978)^{60}$, Saraiva Leão (1981) ${ }^{87}$, Leenen \& Kuypers (1989) ${ }^{64}$ e Pearl et al. $(1985)^{78}$.

\section{Retocolectomia com anastomose ileorretal:}

A baixa experiência decorrente do pequeno número de casos ( 7 cirurgias) justifica o elevado índice de complicações ( 2 complicações, $28,5 \%$ ) sem óbitos $(0 \%)$. Não se trata de uma cirurgia voltada para o CR, não havendo como aferi-la com achados de outros 
autores. O pequeno número de casos não justifica comparação com a literatura.

\section{Proctocolectomia total com ileostomia definitiva:}

Foi realizada apenas 3 vezes (em decorrência de concomitância de outras doenças colorretais, mormente RCUI e FAP), sem complicações ou óbitos. $\mathrm{O}$ número inexpressivo impede qualquer inferência estatística e qualquer comparação. Não se trata de uma cirurgia voltada para o CR, não havendo como aferi-la com achados de outros autores.

\section{Abordagens terapêuticas dos 47 pacientes com complicações cirúrgicas decorrentes de 373 cirurgias por câncer no reto em 380 pacientes:}

As condutas em cada caso dependeram das condições do paciente, da doença, da complicação e dos recursos técnicos de cada época em que os pacientes foram atendidos. Assim, todos os 15 pacientes que desenvolveram deiscência de anastomose foram laparotomizados, mas as técnicas usadas variaram em detrimento das referidas condições, desde 9 colostomias com fechamento do coto, a 2 reanastomoses com estoma protetor e 4 aplicações de pontos na linha anastomótica; da mesma forma, todos os 6 pacientes portadores de estenose de anastomose foram submetidos a nova anastomose e estoma protetor. Recursos técnicos possibilitaram que o último caso de abscesso subfrênico tivesse sido drenado por imagem intervencionista, mas os 42 primeiros somente o foram por laparotomia. $\mathrm{O}$ fato de existirem tantas variáveis na abordagem de uma mesma complicação torna impossível aferir tais dados com os da literatura.

\section{CONCLUSÕES}

1. O câncer retal foi mais comum no terço inferior $(172 ; 45,3 \%)$, seguindo o terço superior (126; $33,1 \%)$ e o médio $(82 ; 21,6 \%)$.

2. A ressecabilidade dos tumores retais de terço superior foi de $88,9 \%$ (112 pacientes), e a retossigmoidectomia abdominal com anastomose manual foi a cirurgia mais praticada (76 pacientes; $60,3 \%)$.
3. A ressecabilidade dos tumores retais de terço médio foi de $90,2 \%$ (72 pacientes), e a retossigmoidectomia abdominal com anastomoses manual e mecânica foi a cirurgia mais praticada (40 pacientes; 48,7\%).

4. A ressecabilidade dos tumores retais de terço inferior foi de $89,5 \%$ (154 pacientes), e a amputação abdominoperineal com colostomia definitiva foi a cirurgia mais praticada (154 pacientes; $74,4 \%$ ).

5. A ressecabilidade tumoral foi elevada (338 pacientes; 88,9\%).

6. As cirurgias mais praticadas foram a amputação abdominoperineal (135 ou $35,5 \%$ ) e a retossigmoidectomia abdominal com anastomose colorretal manual e mecânica $(130 ; 34,3 \%)$.

7. As ocorrências de complicações cirúrgicas imediatas maiores foram de 12,6\% (47 em 380 casos); e a mortalidade cirúrgica foi de $1,6 \%$ (6 casos).

8. As 2 cirurgias mais praticadas apresentaram índices de complicações consideradas baixos: amputação abdominoperineal à Miles com colostomia definitiva - 135 cirurgias com 13 complicações $(9,6 \%)$ e 2 óbitos (1,5\%); e a retossigmoidectomia abdominal tipo Dixon com anastomose manual e mecânica - 130 cirurgias com 19 complicações $(14,6 \%)$ e 2 óbitos $(1,5 \%)$.

9. O maior índice de complicações foi da retossigmoidectomia abdômino-endoanal com anastomose cólon-anal mecânica $(30,7 \%)$; e o menor foi da amputação abdominoperineal $(9,6 \%)$.

10. O maior índice de óbito foi da retossigmoidectomia abdômino-endoanal com anastomose cólon-anal mecânica $(7,7 \%)$; e o menor foi da amputação abdominoperineal $(1,5 \%)$.

11. Dentre as 47 complicações, as mais comuns foram as relacionadas à própria anastomose (15 deiscências e 6 estenoses), seguidas dos abscessos (3 abscessos subfrênicos, 4 abscessos pélvicos e 2 abscessos perineais), da necrose de coto abaixado (4 casos), necrose e desabamento de estoma (4 casos), obstrução de intestino delgado (3 casos), hemorragia ( 4 casos) e lesão cirúrgica do ureter (2 casos).

12. As condutas em cada caso dependeram das condições do paciente, da doença, da evolução e gravidade da complicação e dos recursos técnicos de cada época em que os pacientes foram atendidos. 
SUMMARY: In a 31-year period of practice in Coloproctology, from 1965 to 1996, the author had the opportunity to attend 24,200 patients, bearing $923(3.8 \%)$ cancer of the large bowel. Eight hundred and seventy $(870-3.6 \%)$ of the tumours were colorectal cancer (adenocarcinoma) and $53(0.2 \%)$ were carcinoma of the anus of several hystological types. In 490 cases $(56.3 \%)$ cancer were localized in the colon and $380(43.7 \%)$ in the rectum. The main purpose of this study was to collect data concerning 380 patients bearing rectal cancer attended from 1965 to 1996,373 of them undergoing surgery, with enphasis to surgical techniques specially 47 surgical complications. Cancer were far more common in the upper $(126 ; 33.1 \%)$ and low $(172 ; 45.3 \%)$ than in the middle rectum $(82 ; 21.6 \%)$. Resecability of tumours of the upper rectum reached $88.9 \%$ (112 patients), being abdominal rectosigmoidectomy with handmade anastomosis the most used surgery (76 patients; $60.3 \%$ ). Resecability of tumours of the middle rectum reached $90.2 \%$ (112 patients), being abdominal rectosigmoidectomy with handmade and stappled anastomosis the most used surgery (40 patients; 48.7\%). Resecability of tumours of the low rectum reached $89.5 \%$ (112 patients), being abdominaperineal amputation (Miles) the most used surgery (154 patients; $74.4 \%$ ). Resecability of tumour was very high reaching $88.9 \%$ (338 patients). The most used surgical technique was Miles procedure (135 patients; $35.5 \%$ ) and abdominal rectosigmoidectomy with handmade and stappled anastomosis (130 patients; $34.3 \%$ ). Immediate major surgical complication rate was $12.6 \%$ (47 cases in 380 patients); and mortality rate was $1.6 \%$ ( 6 cases). The two most used surgical techniques presented low complication rate: Miles procedure - 135 surgeries, 13 complications $(9.6 \%)$ and 2 deaths $(1.5 \%)$; and abdominal rectosigmoidectomy with hand made and stappled anastomosis - 130 surgeries, 19 complications $(14.6 \%)$ and 2 deaths $(1.5 \%)$. The highest immediate major surgical complication rate was caused by endoanal rectosigmoidectomy and stappled colon to anus anastomosis $(30.7 \%)$; and the lowest was due to Miles procedure $(9.6 \%)$. The highest mortality rate was caused by endoanal rectosigmoidectomy and stappled colon to anus anastomosis (7.7\%); and the lowest was due to Miles procedure (1.5\%). The most common among the 47 complications were due to the anastomosis (15 cases of leakage and 6 cases of stenosis), following: abscesses ( 3 cases of abdominal, 4 cases of pelvic and 2 cases of perineal abscesses), necrosis of the rectal stump ( 4 cases), necrosis of colostomy ( 4 cases), small bowell obstruction ( 3 cases), hemorrhage (4 cases) and surgical lesion of the left urether ( 2 cases). Surgical procudure in each case of complication depended on conditions of the patient, of the disease, of the evolution and severity of the complication and of the technical resources of each time when the patients were attended.

Key words:Complications in surgery for rectal cancer; surgery in rectal cancer; rectal cancer; rectal surgery.

\section{REFERÊNCIAS BIBLIOGRÁFICAS}

1. Antosen HK, Bronborg O. Early complication after low anterior resection for rectal cancer using the EEA TM stapling device: a prospective trial. Dis Colon Rectum, 1987; 30:579583.

2. Baslev \& Harling, 1983. In Cruz,1991.

3. Beck DE \& Wexner SD. Fundamentals of Anorectal Surgery. W B Saunders Company Ltd., 1992

4. Beck DE, Fazio VW. Premalignant lesions of the anal margins. South Med J, 1989; 82:470-4.

5. Bernstein, WC \& Bernstein EF. Sexual dysfunction following radical surgery for cancer of the rectum. Dis Colon Rect 1966;9:328-332.

6. Beynon J, Mortesen. NJ, Foy DM, Channer Jl, Rigby H, Virjee $\mathrm{J}>$ The detection and evaluation of locally recurrent rectal cancer with rectal endonosography. Dis Colon Rectum 1989;32:509-17.

7. Beynon J. Mortensen NJMcC,Foy DMA et al: Preoperative assessment of local invasion in retal cancer: Digital examination, endoluminal sonography or computed tomography? Br J Surg 1986;73:1015-1017.
8. Bokey E1, Chapuis PH, Hughes WJ, Joorey SG. Morbidity, mortaliy, mortality and survival following resection or carcinoma of the rectum of Concord Hospital. Aust N Z J Surg 1990;60:253.

9. Bordos DC, Baker RR, Cameron JL. An evaluation of palliative abdominoperineal resection for carcinoma of the rectum. Surg Gynecol Obstet 1974;139:731-733.

10. Broadwell D.C e Jackson BS. Principles of ostomy care. St. Louis Mosby 1982.

11. Burgos FJ, Romero J, Fernández E, Perales L, Tallada M. Risk factor for developing voiding dysfunction after abdominoperineal resection for adenocarcinoma of the rectum. Dis Colon Rectum, 1988; 31:682-7.

12. Chassin JL. Operative Strategy in General Surgery - An Expositive Atlas -. Springer-Verlag, New York, 1980.

13. Coller JA, Murray JJ. Equipment. In: Ballantine GH, Leahy PF, Modlen IM. Laparoscopic Surgery. Philadelphia, W.B.Saunders Company, 1994.

14. Corman ML: Colon and Rectal Surgery. Philadelphia. JB Lippincott Company 1989. 
15. Cruz GMG e Alexandrino, J. Leiomiossarcoma do Reto. Revista da Associação Médica de Minas Gerais 1975, 26 (1/ 2): 25-30.

16. Cruz GMG. Câncer Colorretal em Pacientes com Menos de 40 anos de Idade. Revista Brasileira de Proctologia 1991; II(1):19-24,.

17. Cruz GMG. Tumores Malignos do Ânus e Canal Anal. In: Tópicos em Gastroenterologia, Paula-Castro L Savassi-Rocha PR, Carvalho DG. MEDSI Editora Médica e Científica Ltda 1992; 4:83-112.

18. Cruz GMG. Câncer do Reto. In: Atualidades em Coloproctologia, Moreira H, Fundo Editorial BYK, São Paulo, 1996;03 - 54

19. Cruz GMG. Câncer Colorretal Metacrônico: Estudo da Incidência Cumulativa e Apresentação de 10 Casos Pessoais. Revista da Sociedade Brasileira de Coloproctologia 1996; 16(3): 121-128.

20. Cruz GMG. et als. Anatomia e Histologia da Região Anorretal. In: Cruz GMG. Livro Texto "Coloproctologia”, Volume I "Coloproctologia - Propedêutica Geral”, Editora Revinter, Rio de Janeiro, RJ, 1998; I; 003: 21-32.

21. Cruz GMG et al. Câncer no Ânus e Canal Anal. In: Cruz GMG. Livro Texto "Coloproctologia", Volume II - "Coloproctologia - Propedêutica Nosológica”, Editora Revinter, Rio de Janeiro, RJ, 1999; VII; 081: 1187-1200.

22. Cruz GMG. Técnica Cirúrgica: Grampeadores e Anastomoses Mecânicas. In: Cruz GMG. Livro Texto "Coloproctologia", Volume III - "Coloproctologia - Terapêutica”, Editora Revinter, Rio de Janeiro, 2000; XI; 113: 1554-1567.

23. Cruz GMG. Princípios Técnicos da Cirurgia Anorretoperineal. In: Cruz GMG - Livro Texto "Coloproctologia", Volume III - "Coloproctologia - Terapêutica”, Editora Revinter, Rio de Janeiro, RJ, 2000; XI; 114: 1568-1578.

24. Cruz GMG. Princípios Técnicos da Cirurgia dos Estomas Intestinais. In: Cruz GMG. Livro Texto "Coloproctologia", Volume III - "Coloproctologia - Terapêutica", Editora Revinter, Rio de Janeiro, RJ, 2000; XI; 115: 1579-1607.

25. Cruz GMG. Tratamento Cirúrgico do Câncer no Reto. In: Cruz GMG. Livro Texto "Coloproctologia", Volume III "Coloproctologia - Terapêutica", Editora Revinter, Rio de Janeiro, RJ, 2000; XV; 146: 1915-1954.

26. Cruz GMG. Câncer no Reto: Experiência Pessoal. In: Cruz GMG. Livro Texto "Coloproctologia", Volume III "Coloproctologia - Terapêutica", Editora Revinter, Rio de Janeiro, RJ, 2000; XV; 147: 1955-1980.

27. Cruz GMG. Estudo Retrospectivo de uma Casuística de 380 casos de Câncer Retal ao Longo de Quatro Décadas. Tese de Doutorado apresentada ao Programa de Pós-Graduação da Santa Casa de Belo Horizonte. ISBN - 85-903214-1-X, 2002.

28. Cukier J. Les complications uréthro-vésicales de la chirurgie d"exérese élargie du cancer du rectum. Cah Med 1970; 11: 57-62.
29. Cunsolo A, Bragaglia RB, Manara G, Pogglioli G, Gozzetti G. Urogenital dysfunction after abdominoperineal resection for carcinoma of the rectum. Dis Colon Rectum 1990;33:918.

30. Cunsolo A, Bragaglia RB, Petrucci C, Gozetti G. Survival and complications after radical surgery for carcinoma of the rectum. J Surg Oncol 1989;41-27.

31. Cutait DE, Cutait R, Ioshimoto M, et al. Abdominoperineal endoanal pullthrough resection. Dis Colon Rectum 1985;28:294-299.

32. Cutait R., Word R. Cirurgia ampliada em câncer colorretal. In: Cruz GMG. Livro Texto "Coloproctologia", Volume III "Coloproctologia - Terapêutica", Editora Revinter, Rio de Janeiro, RJ, 2000; III; 181: 2296-2298.

33. Czerny V: Casuistische mittheilungen aus der chirurg P11. Klin zu Heidelberg. Munch Med Wchnschr 1894.

34. Deddish MR, Stearns MW Jr: Anterior resection for carcinoma of the rectum and rectosigmoid area. Am Surg 1961;961-966.

35. Eickerberg HU, Amith M Klompus W. Lich R. Urologic complications following abdominoperineal resection. J Urol 1976;115:180.

36. Enker WE, Laffer UT, Block GE. Enhanced of patients with colon and rectal cancer is based upon wide anatomic resection.Ann Surg 1979;190:350-360.

37. Fazio VW. Advances in the surgery of rectal carcinoma utilizing the surgical stapler. En: Spratt JS (ed): Neoplasms of the Colon, Rectum and Anus: Mucosal and Epithelial. Philadealphia: WB Saunders \& Co 1984;268-88.

38. Fisher B. Postoperative adjuvant chemotherapy or radiation therapy for rectal cancer: results from NSABP Protocol R-01. JNCI, 1988; 80:21-28.

39. Gerstenverg TC, Nielsen ML, Clausen S, Blaabjerg J. Lindenberg J. Bladder function after abdominoperineal resection of the rectum for anorectal cancer; urodynamic investigation before and after operation in a consecutive series. Ann Surg 1980;191-201.

40. Gillen P, Peel ALG. Comparison of mortality, morbidity and incidence of local recurrence in patients with rectal cancer treated by either stapled anterior resection or abdominoperineal resection. Br J Surg 1986:73:339.

41. Glenn F, McSherry CK. Carcinoma of the distal large bowel: 32-year review of 1026 cases. Ann Surg 1966;163:838-849.

42. Glockner MR e Sterling JR. "Providing sexual information to ostomy patients". Dis Colon Rectum 1982;25(6):575-579.

43. Goligher JC, Duthie HL, DeDomabal FT et al. Abdominoanal pull-through excision for tumors of the mid-third of rectum: A comparison with low anterior resection. Br J Surg 1965;52:323-334.

44. Goligher JC. Cirurgia do Ânus, Reto e Cólon, $5^{\text {a }}$ ed., Editora Manole Ltda; 1990.

45. Goligher JC. Further reflection on preservation of the anal sphincters in the radical treatment of rectal cancer. Proc $\mathrm{R}$ Soc Med, 1962; 55:341-6. 
46. Gordon PH, Nivatvongs S. Principles and Practice of Surgery for the colon, Rectum and Anus. 2nd. Ed. Quality Medical Publishing, Inc., St. Louis, Missouri, 1999

47. Green EW. "Colostomies and their complications". Surg Gynec Obst 1966;122:1230-1232.

48. Habr-Gama A, Alves PRA. Câncer do ânus. In: Corrêa Neto A. Clínica cirúrgica Alípio Corrêa Neto. São Paulo: Sarvier, 1994; 68:676-82.

49. Habr-Gama A, Sousa AHS Jr. Câncer do ânus. In: Pinotti HW. Tratado de clínica cirúrgica do aparelho digestivo. São Paulo: Atheneu, 1994; 156:1293-1300.

50. Habr-Gama A. Câncer no Reto. In: Pinotti HW: Tratado de Clínica Cirúrgica do Aparelho Digestivo. Ed. Atheneu, São Paulo, 1994; cap. 155:1273-1292.

51. Habr-Gama A. Indicações e resultados da retocolectomia abdominoendoanal no tratamento do câncer no reto. Tese apresentada à Faculdade de Medicina da Universidade Federal de São Paulo, 1972.

52. Halpem NB, Cox CB, Aldrete JS. Abdominoperineal resection for rectal carcinoma: Perioperative risk factors. S Med J 1989;82:1492.

53. Heald RJ, Ryall RDH. Recurrence and survival after total mesorectal excision for rectal cancer. Lancet 1986;1:14791482.

54. Hughes ESR, Cuthbertson AM \& Carden ABC. Pull-through operations for carcinoma of the rectum. Med J Aust 1962;49:907-909.

55. Keighley MRB, Pemberton JH, Fazio VW, Parc R. Surgical Skills: Atlas of Colorectal Surgery. Churchill Levingstone Inc., USA, 1996

56. Keighley MRB, Williams NS. Surgery of the Anus, Rectum and Colon, W.B. Saunders Company Ttd, 1997.

57. Kewenter J, Brevinge H, Engaras B, Haglind E, Ahren C. Follow-up after secreening for colorectal neoplasms with fecal occult blood testing in a controlled trial. Dis Colon Rectum 1994; 37:115-9.

58. Khubchandani IT, Karamchandani MC, Sheets JA et al. The Bacon pull-through procedure. Dis Colon Rectum 1987;30:540-544.

59. Klinn AC, Ohman U. Bladder and sexual function after surgery for rectal cancer. Dis Colon Rectum 1986;29:43-48.

60. Kretschmer KP. The Intestinal Stoma. Georg Thieme Verlag, Stuttgart, 1978

61. Kruyt RH et al. Normal anorectum: dynamic MRI anatomy. Radiology 1991;179:159-63.

62. Lahey (1930). In Cruz, 2000

63. Larach JS. Operación de Miles. In Azolas CS, Jensen CB: Proctologia Práctica, Chile, Arancibia Hnos y Cía Ltda, 1992:216-20.

64. Leenen LPH, Kuypers JHC. Some factors influencing the outcome of stoma surgery. Dis Colon Rectum 1989;32(6):500504.
65. Lloyd Davies OV. Lithotomy - Trendelenburg position for resection of rectum and lower pelvic colon. Lancet 1939;2:7476.

66. Localio SA, Eng K, Gouge TH, Ranson JHC. Abdominosacral resection for carcinoma of the mid-rectum: Ten years experience. Ann Surg 1978;188:475-480.

67. Lockhart-Mummery HE, Ritchie JK, Hawley PR. The Results of surgical treatment for carcinoma of the rectum at St. Mark's Hospital from 1948 to 1972. Br J Surg 1976;63:673677.

68. Lockhart-Mummery JP. Two hundred cases of cancer of the rectum treated by perineal excisin. Br J Surg 1926;14:110124.

69. Maclennan G, Stogryn RD, Voitk AJ. Abdominoperineal resection: Treatment of choice for carcinoma of the rectum. Cancer 1976;38:953-956.

70. Miles WE. A method of performing abdomino-perineal excision for carcinoma of the rectum and the terminal portion of the pelvic colon. Lancet 1908;2:1812-1813.

71. Neville R, Fielding LP, Amendola C. Local tumor recurence after curative resection for rectal cancer: a ten-year hospital review. Dis Colon Rectum, 1987; 30:12-17.

72. Nicholls RJ, Mason AJ, Marson BC, Dixon AK, Fry IK. The clinical staging of rectal cancer. Br J Surg 1982;69:404-9.

73. Page M, Dalifard I, Bertrand G. Immunostaining of colorectal cancer with monoclonal anti-CEA antibodies compared to serum and tumor CEA content. Anticancer Res, 1986; 6:8936.

74. Pahlman L, Glimelius B. Local recurences after surgical treatment for rectal carcinoma. Acta Chir Scand, 1984; 159:3315 .

75. Palumbo LT, Sharpe WS. Anterior versus abdominoperineal resection: Resection or rectal and rectosigmoid carcinoma. Am J Surg 1968;115:657-600.

76. Papillon J. New prospects in the conservative treatment of rectal cancer. Dis Colon Rectum 1984;27:695-700.

77. Patel, 1977. In Cruz,1991.

78. Pearl RK et al. Early local complications from intestinal stomas. Arch Surg 1985;120:1145-1147.

79. Phillips RKS. Colorectal Surgery - A companion to specialist surgical practice. WB Saunders Company Ltd., 1998.

80. Racitch MM, Steichen FM. Principles and Practice of Surgical Stapling. Chicago, Year Book Medical Publishers, 1987.

81. Ramos JR, Regadas FSP, Souza JS. Cirurgia Colorretal por Videolaparoscopia. Rio de Janeiro, RJ, 1997.

82. Rosato GO.Fisiologia Anorrectal Enfoque Practico Atualização em coloproctologia 1995, 14 Congresso Latinoamericano de Coloproctologia, pp234-236.

83. Rosen L, Veidenheimer MV, Coller JA, Corman ML. Mortality, morbidity, and patterns of recurrence after abdominal resection for cancer the rectum. Dis Colon Rectum 1982;25:202208. 
84. Rothenberger, 1990. In Cruz,1991.

85. Santangelo ML, Romano G. Sassoroli C. Sexual function after resection for rectal cancer. Am J Surg 1987;154:502.

86. Santy P, Michaud P, Replumaz P. Resultats de la conservation du sphincter dans la chirurgie du cancer du rectum. Lyon chir 1951;54:385-392.

87. Saraiva Leão PH. Propedêutica das ileostomias e colostomias. In: Cruz GMG. Livro Texto "Coloproctologia", Volume I "Coloproctologia - Propedêutica Geral", Editora Revinter, Rio de Janeiro, RJ, ISBN 85-7309-302-1. 1998; I; 051: 683-689.

88. Schiller KFR, Cockel R, Hunt R. Atlas de Endoscopia Gastrintestinal. Tradução. RevinteR, Rio de Janeiro, 1995.

89. Shepard, 1971. In Cruz,1991.

90. Slanetz (1972). In Cruz,1991.

91. Stearns MW Jr. Carcinoma of the rectum: Results of abdominoperineal resection (symposium). Dias Colon Rectum 1974; 17:586-587.

92. Strauss RJ, Friedman M, Platt N, Wise L. Surgical treatment of rectal carcinoma: Results of anterior resection vs abdominoperineal resection at a community hospital. Dis Colon Rectum 1978;21:269-276.

93. Walz BJ, Lindstrom ER, Butcher HR, Butcher HR Jr, Baglan RJ. Natural History of patients after abdominal perineal resection: Implications for radiation therapy. Cancer 1977;39:2437-2442.

94. Weishaupt RA, Cabrera AM, Vial CG. Sobrevida y seguimiento de resecciones curativas del cáncer rectal. In Azolas CS, Jensen CB (eds): Proctologia Practica, lst ed. Santiago, Chile, Arancibia HNOS y Cía Ltda 1992:225-231.

95. Welter R, Patel JC. Chirurgie Mecanique Digestive. Paris. Masson, 1985.
96. Wheeless CR Jr. Atlas of Pelvic Surgery, $2^{\text {nd }}$ Edition. Philadelphia, Lea \& Febiger, 1988.

97. Wibe A et al. (2000). In Cruz, 2000.

98. Williams N. Colorectal Cancer. Churchill Levingstone, London, 1996

99. Williams RD, Yurko AA, Kerr G, Zollinger RM. Comparison of anterior and abdominoperineal resection for low pelvic colon and rectal carcinoma. Am J Surg 1966;111:114-119.

100. Wolmark N, Fisher B, Wieaund HS. The prognostic value of Duke's classfication of colorectal cancer: an analysis of the NASSBP clinical trials. Ann Surg, 1986; 203:115-22.

101. Yeager ES, Van Heerden JÁ. Sexual dysfunction following proctocolectomy and abdominoperineal resection. Ann Surg 1980;191:169

102. Zollinger RM, Sheppard MH. Carcinoma of the rectum and the restosigmoid: A review of 729 cases. Arch Surg 1971;102:335-338.

\section{Endereço para correspondência:}

GERALDO MAGELA GOMES DA CRUZ

Rua Rio de Janeiro, 2017 - ap. 1401 - Lourdes

30.160-042 - Belo Horizonte (MG) 